\title{
Exploring Return Transmission in Asian Stock Markets
}

\author{
Chikashi Tsuji \\ Professor, Faculty of Economics, Chuo University \\ 742-1 Higashinakano, Hachioji-shi, Tokyo 192-0393, Japan \\ E-mail: mail_sec_low@minos.ocn.ne.jp
}

Received: August 19, 2019 Accepted: Oct. 8, $2019 \quad$ Published: October 8, 2019

doi:10.5296/jmr.v11i4.15533ＵRL: https://doi.org/10.5296/jmr.v11i4.15533

\begin{abstract}
This paper investigates the return transmission between four Asian stock markets in Japan, China, Korea, and Taiwan. Specifically, applying a vector autoregression (VAR) model, this study derives the following interesting findings and interpretations. First, our results reveal that (1) rapid cross-country and autoregressive return transmission between the four Asian stock markets recently decreased, and (2) recently, the effects from the Japanese stock market to the other three Asian stock markets became weaker. Furthermore, our results clarify that (3) the return transmission effect from the Chinese stock market to the other three Asian stock markets is generally weak, also meaning that the Chinese stock market evolves autonomously.
\end{abstract}

Keywords: Asian stock market, return transmission, VAR model 


\section{Introduction}

The return linkages between international equity markets have recently been the subject of investigation by both academic researchers and industry participants, and there are some extant studies on return transmission in financial markets (e.g., Arouri et al., 2011a, 2011b, 2012; Sadorsky, 2012; Syriopoulos et al., 2015; Tsuji, 2018a, 2018b, 2019). However, regardless of its significance, existing studies focusing on return transmission in Asian stock markets are limited.

Based on this, this study empirically examines how return transmission arises in Asian stock markets. More specifically, applying a vector autoregression (VAR) model, this paper investigates the return transmission between four Asian stock markets in Japan, China, Korea, and Taiwan. Our research question is how return transmission arises and changes over time between the four markets; and thus we use two subsample periods and compare the results. As a result, our current study derives the following interesting findings.

That is, for our former subsample period, first, (1) Japanese stock returns transmit to the next day's Chinese, Korean, and Taiwanese stock returns. Second, (2) Korean stock returns transmit to the next day's Japanese and Taiwanese stock returns. Third, (3) Taiwanese stock returns transmit to the next day's Korean stock returns. Fourth, (4) Chinese stock returns transmit to their own future stock returns. Fifth, (5) Korean stock returns transmit to their own future stock returns. Sixth, (6) Taiwanese stock returns transmit to their own future stock returns. Furthermore, for our latter subsample period, first, (1) we find that Korean stock returns transmit to the next day's Japanese and Taiwanese stock returns. Second, (2) Korean stock returns again transmit to their own future stock returns.

As regards the rest of this paper, Section 2 reviews recent literature, Section 3 explains our data, and Section 4 documents our methods. Section 5 explains our results, and Section 6 concludes the paper.

\section{Recent literature review}

This section briefly reviews several recent extant studies. As we noted, existing studies focusing on return transmission in Asian stock markets are limited, hence extant studies reviewed in this section do not always focus on Asian stock markets. First, focusing on the six Gulf Cooperation Council countries, Arouri et al. (2011b) investigated return and volatility transmission between crude oil and the six stock markets of Kuwait, Qatar, Saudi Arabia, the United Arab Emirates, Bahrain, and Oman. They found evidence of return and volatility transmission effects between crude oil and the six stock markets in most cases.

Further, focusing on financial markets in India, Roy and Roy (2017) investigated not return transmission but volatility spillovers between stock, bond, exchange rate, gold, and commodity markets, and they found that in India, the stock and commodity markets were net volatility transmitters, while the bond, gold, and foreign exchange markets were net volatility receivers. Moreover, using high-frequency data of Shanghai and Hong Kong stock market indices, Huo and Ahmed (2017) examined the impact of the recent Shanghai-Hong Kong Stock Connect, and found that after the connection, the volatility spillover effects from 


\section{Ml Macrothink}

Journal of Management Research

ISSN 1941-899X

2019, Vol. 11, No. 4

Shanghai to Hong Kong became stronger. Lastly, Tsuji (2018a) examined return and volatility transmission between crude oil and international oil equities, including the Far East and BRIC (Brazil, Russia, India, and China) regions, and found evidence of return transmission from crude oil to the oil equities of the Far East and BRIC.

As above, we understand that although several studies analyzed return transmission in Asian markets; however, again, existing studies focusing on return transmission in Asian stock markets are limited. Therefore, in this paper, by using Japanese, Chinese, Korean, and Taiwanese stock return data, we investigate the return transmission effects between the four markets in the framework of VAR analyses.

\section{Data}

This section explains our data for this study. Using raw stock price data from Thomson Reuters, we construct four daily log difference percentage stock price index returns. More concretely, JPLR denotes the log return of the Nikkei 225 stock average; CHLR denotes the log return of the Shanghai Stock Exchange A Share; KORLR is that of the Korea Stock Exchange Composite; and TWLR is that of the Taiwan Stock Exchange Weighed. The full sample period of these returns is from January 3, 1992 to September 20, 2019. The former and latter subsample periods are January 3, 1992 to December 30, 2005, and January 2, 2006 to September 20, 2019, respectively.

Figure 1 plots the evolution of the above four stock price indices for our full sample period. Table 1 displays the summary statistics regarding the four stock returns. As Panel A of Table 1 shows, in the former subsample period, the standard deviation for CHLR is high, the skewness for CHLR is large with positive values, and the kurtosis for CHLR shows particularly high values. Further, as in Panel B of Table 1, in the latter subsample period, the skewness values for all the four stock returns are negative, and all of the kurtosis values are higher than the corresponding values in Panel A of Table 1 except for that of CHLR.

\section{Models and methods}

This section describes our analyzing methodology. In this study, to examine the return transmission effects between the four Asian stock markets, we use a five-lag VAR model as follows:

$$
\begin{aligned}
r_{i, t}=c_{i}+\sum_{j=1}^{4} a_{i, j} r_{j, t-1} & +\sum_{j=1}^{4} b_{i, j} r_{j, t-2}+\sum_{j=1}^{4} d_{i, j} r_{j, t-3} \\
& +\sum_{j=1}^{4} e_{i, j} r_{j, t-4}+\sum_{j=1}^{4} f_{i, j} r_{j, t-5}+\varepsilon_{i, t}, \text { for } i=1, \ldots, 4 .
\end{aligned}
$$

In equation (1), $r_{i, t}$ denotes the stock return $i ; r_{j, t-k}$ is the $k$ th lag of stock return $j ; c_{i}, a_{i, j}, b_{i, j}, d_{i, j}$, $e_{i, j}$, and $f_{i, j}$ are the coefficients; and $\varepsilon_{i, t}$ is the error term. In this study, we are interested in the rapid return transmission between the four Asian stock markets, but one week includes five business days; thus we employ a five-lag VAR model in this study. We note that in equation (1), we specify Japanese, Chinese, Korean, and Taiwanese stock returns as $i=1$ to 4 throughout the paper. 
Table 1. Summary statistics for the daily log stock returns of four Asian countries

Panel A. Former subsample period from January 3, 1992 to December 30, 2005

\begin{tabular}{lclll}
\hline Statistic & JPLR & CHLR & KORLR & TWLR \\
\hline Mean & -0.010 & 0.039 & 0.022 & 0.010 \\
Median & 0.000 & 0.000 & 0.000 & 0.000 \\
Max. & 7.660 & 74.517 & 10.024 & 8.520 \\
Min. & -7.234 & -18.427 & -12.805 & -9.936 \\
SD & 1.409 & 2.831 & 1.927 & 1.591 \\
Skewness & 0.083 & 6.167 & -0.066 & -0.041 \\
Kurtosis & 5.452 & 148.769 & 7.032 & 5.658 \\
JB & 918.940 & 3255592.127 & 2475.865 & 1075.815 \\
$p$-value & 0.000 & 0.000 & 0.000 & 0.000 \\
\hline
\end{tabular}

Panel B. Latter subsample period from January 2, 2006 to September 20, 2019

\begin{tabular}{lllll}
\hline Statistic & JPLR & CHLR & KORLR & TWLR \\
\hline Mean & 0.009 & 0.026 & 0.012 & 0.014 \\
Median & 0.000 & 0.015 & 0.004 & 0.016 \\
Max. & 13.235 & 9.033 & 11.284 & 6.525 \\
Min. & -12.111 & -9.261 & -11.172 & -6.735 \\
SD & 1.470 & 1.595 & 1.190 & 1.118 \\
Skewness & -0.527 & -0.640 & -0.611 & -0.492 \\
Kurtosis & 11.707 & 7.931 & 13.521 & 7.749 \\
JB & 11473.209 & 3871.896 & 16734.803 & 3508.900 \\
$p$-value & 0.000 & 0.000 & 0.000 & 0.000 \\
\hline Notes: Pants A and & B & 0.000 &
\end{tabular}

Notes: Panels A and B include daily 3651 and 3580 observations, respectively.

JPLR: Japanese stock return; CHLR: Chinese stock return; KORLR: Korean stock return; TWLR: Taiwanese stock return.

Max.: maximum value; Min.: minimum value; SD: standard deviation; JB: Jarque-Bera statistic. 
Panel A. Japan

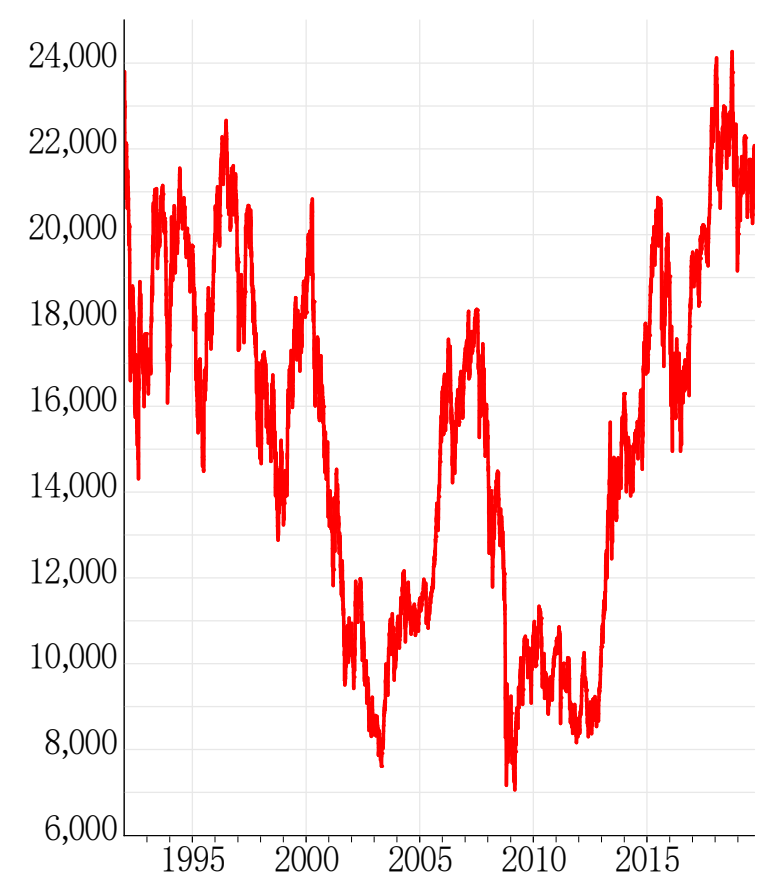

Panel C. Korea

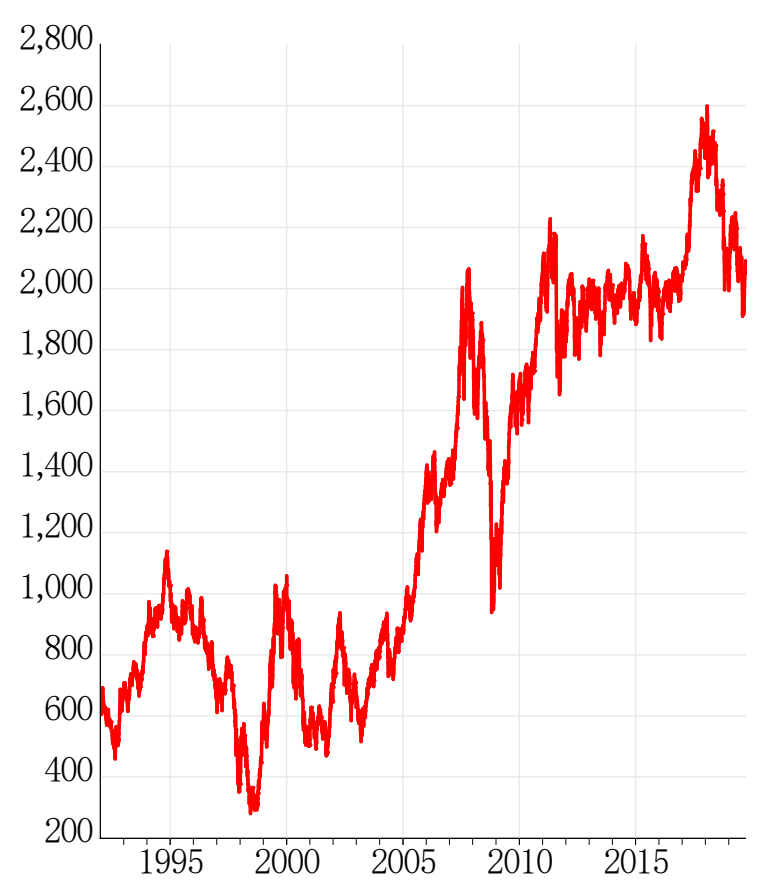

Panel B. China

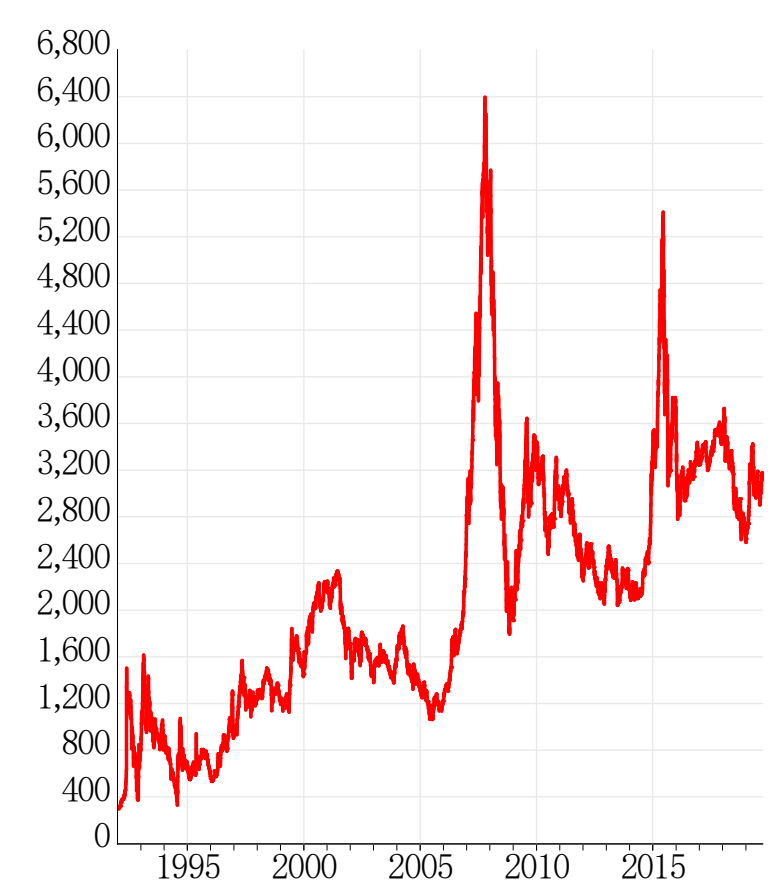

Panel D. Taiwan

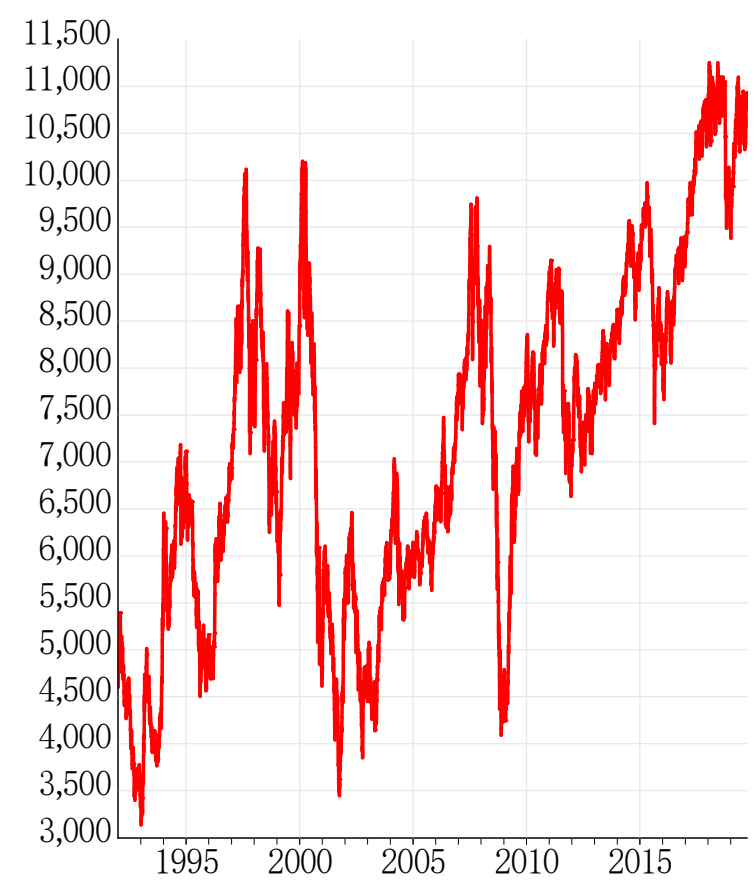

Figure 1. Price evolution in stock markets for Japan, China, Korea, and Taiwan 
Table 2. Estimation results of the VAR model for the former subsample period from January 3, 1992 to December 30, 2005

\begin{tabular}{|c|c|c|c|c|}
\hline & JPLR & CHLR & KORLR & TWLR \\
\hline $\operatorname{JPLR}(-1)$ & $-0.058 * * *$ & $0.060 *$ & $0.041 *$ & $0.086 * * *$ \\
\hline$p$-value & 0.001 & 0.088 & 0.084 & 0.000 \\
\hline $\operatorname{JPLR}(-2)$ & $-0.039 * *$ & 0.008 & -0.018 & 0.003 \\
\hline$p$-value & 0.027 & 0.816 & 0.446 & 0.878 \\
\hline $\operatorname{JPLR}(-3)$ & 0.004 & 0.033 & $0.061 * *$ & 0.004 \\
\hline$p$-value & 0.838 & 0.349 & 0.011 & 0.846 \\
\hline $\operatorname{JPLR}(-4)$ & 0.009 & -0.040 & 0.007 & 0.003 \\
\hline$p$-value & 0.614 & 0.255 & 0.758 & 0.888 \\
\hline $\operatorname{JPLR}(-5)$ & 0.004 & -0.012 & -0.021 & -0.008 \\
\hline$p$-value & 0.813 & 0.732 & 0.367 & 0.668 \\
\hline $\operatorname{CHLR}(-1)$ & -0.009 & $0.037 * *$ & $-2.4 \mathrm{E}-04$ & 0.004 \\
\hline$p$-value & 0.301 & 0.024 & 0.983 & 0.632 \\
\hline $\operatorname{CHLR}(-2)$ & 0.003 & $0.036 * *$ & -0.015 & $-0.015^{*}$ \\
\hline$p$-value & 0.672 & 0.031 & 0.191 & 0.098 \\
\hline $\operatorname{CHLR}(-3)$ & -0.007 & $0.041 * *$ & 0.002 & -0.007 \\
\hline$p$-value & 0.393 & 0.014 & 0.848 & 0.427 \\
\hline $\operatorname{CHLR}(-4)$ & $-4.4 \mathrm{E}-05$ & 0.026 & 0.006 & 0.011 \\
\hline$p$-value & 0.996 & 0.121 & 0.611 & 0.241 \\
\hline $\operatorname{CHLR}(-5)$ & 0.002 & 0.022 & -0.001 & -0.010 \\
\hline$p$-value & 0.839 & 0.185 & 0.927 & 0.271 \\
\hline KORLR $(-1)$ & $0.048 * * *$ & -0.016 & $0.043 * *$ & $0.048 * * *$ \\
\hline$p$-value & 0.000 & 0.536 & 0.014 & 0.001 \\
\hline KORLR(-2) & 0.011 & -0.005 & -0.022 & 0.002 \\
\hline$p$-value & 0.371 & 0.843 & 0.217 & 0.899 \\
\hline $\operatorname{KORLR}(-3)$ & -0.008 & 0.008 & -0.024 & -0.021 \\
\hline
\end{tabular}




\begin{tabular}{|c|c|c|c|c|}
\hline$p$-value & 0.532 & 0.767 & 0.172 & 0.137 \\
\hline $\operatorname{KORLR}(-4)$ & -0.008 & -0.012 & -0.018 & -0.012 \\
\hline$p$-value & 0.528 & 0.653 & 0.303 & 0.408 \\
\hline KORLR(-5) & 0.002 & -0.007 & $-0.031 *$ & $0.040 * * *$ \\
\hline$p$-value & 0.883 & 0.777 & 0.076 & 0.005 \\
\hline $\operatorname{TWLR}(-1)$ & 0.021 & 0.025 & $0.039 *$ & -0.009 \\
\hline$p$-value & 0.179 & 0.421 & 0.064 & 0.616 \\
\hline $\operatorname{TWLR}(-2)$ & -0.010 & -0.004 & 0.017 & $0.034 * *$ \\
\hline$p$-value & 0.495 & 0.885 & 0.409 & 0.046 \\
\hline $\operatorname{TWLR}(-3)$ & 0.003 & 0.039 & 0.018 & $0.039 * *$ \\
\hline$p$-value & 0.835 & 0.206 & 0.380 & 0.023 \\
\hline $\operatorname{TWLR}(-4)$ & -0.003 & 0.046 & $-0.043^{* *}$ & $-0.051 * * *$ \\
\hline$p$-value & 0.825 & 0.136 & 0.041 & 0.003 \\
\hline TWLR $(-5)$ & 0.001 & 0.039 & 0.016 & 0.023 \\
\hline$p$-value & 0.958 & 0.198 & 0.445 & 0.172 \\
\hline Const. & -0.011 & 0.032 & 0.023 & 0.008 \\
\hline$p$-value & 0.627 & 0.495 & 0.473 & 0.749 \\
\hline LL & -6402.253 & -8951.306 & -7541.107 & -6828.686 \\
\hline AIC & 3.523 & 4.922 & 4.148 & 3.757 \\
\hline $\mathrm{SC}$ & 3.559 & 4.957 & 4.184 & 3.793 \\
\hline
\end{tabular}

Notes: JPLR: Japanese stock return; CHLR: Chinese stock return; KORLR: Korean stock return; TWLR: Taiwanese stock return.

$\operatorname{JPLR}(-k)$ : the $k$ th lag of Japanese stock return; CHLR $(-k)$ : the $k$ th lag of Chinese stock return; KORLR $(-k)$ : the $k$ th lag of Korean stock return; TWLR $(-k)$ : the $k$ th lag of Taiwanese stock return; Const.: constant term of the VAR model.

$* * *, * *$, and $*$ denote $1 \%, 5 \%$, and $10 \%$ significance levels, respectively.

Bold figures mean statistically significantly positive parameter estimates.

LL: the log-likelihood value.

AIC: Akaike's Information Criterion.

SC: Schwarz Criterion. 
Table 3. Estimation results of the VAR model for the latter subsample period from January 2, 2006 to September 20, 2019

\begin{tabular}{|c|c|c|c|c|}
\hline & JPLR & CHLR & KORLR & TWLR \\
\hline $\operatorname{JPLR}(-1)$ & $-0.097 * * *$ & -0.022 & $-0.044 * *$ & -0.008 \\
\hline$p$-value & 0.000 & 0.358 & 0.012 & 0.650 \\
\hline $\operatorname{JPLR}(-2)$ & $-0.039^{*}$ & -0.002 & 0.010 & 0.013 \\
\hline$p$-value & 0.075 & 0.944 & 0.554 & 0.425 \\
\hline $\operatorname{JPLR}(-3)$ & $-0.051 * *$ & -0.013 & $-0.033^{*}$ & -0.020 \\
\hline$p$-value & 0.019 & 0.579 & 0.060 & 0.225 \\
\hline $\operatorname{JPLR}(-4)$ & $0.036 *$ & $0.040 *$ & 0.010 & -0.010 \\
\hline$p$-value & 0.099 & 0.089 & 0.554 & 0.529 \\
\hline $\operatorname{JPLR}(-5)$ & 0.023 & -0.031 & 0.019 & 0.007 \\
\hline$p$-value & 0.293 & 0.198 & 0.294 & 0.671 \\
\hline CHLR(-1) & -0.024 & 0.008 & $-0.032 * *$ & -0.010 \\
\hline$p$-value & 0.147 & 0.640 & 0.016 & 0.447 \\
\hline CHLR(-2) & 0.004 & -0.024 & $0.025 *$ & -0.002 \\
\hline$p$-value & 0.825 & 0.185 & 0.057 & 0.880 \\
\hline CHLR(-3) & 0.004 & $0.030 *$ & -0.013 & -0.002 \\
\hline$p$-value & 0.790 & 0.094 & 0.320 & 0.851 \\
\hline $\operatorname{CHLR}(-4)$ & 0.001 & $0.058 * * *$ & 0.000 & 0.002 \\
\hline$p$-value & 0.945 & 0.001 & 0.984 & 0.866 \\
\hline CHLR(-5) & -0.013 & 0.003 & -0.017 & -0.010 \\
\hline$p$-value & 0.446 & 0.856 & 0.205 & 0.418 \\
\hline $\operatorname{KORLR}(-1)$ & $0.130 * * *$ & 0.047 & $0.045 *$ & $0.101 * * *$ \\
\hline$p$-value & 0.000 & 0.156 & 0.069 & 0.000 \\
\hline $\operatorname{KORLR}(-2)$ & 0.008 & -0.014 & -0.025 & -0.007 \\
\hline$p$-value & 0.784 & 0.686 & 0.322 & 0.780 \\
\hline $\operatorname{KORLR}(-3)$ & 0.002 & -0.022 & 0.030 & $0.044 *$ \\
\hline
\end{tabular}




\begin{tabular}{|c|c|c|c|c|}
\hline$p$-value & 0.941 & 0.501 & 0.222 & 0.062 \\
\hline $\operatorname{KORLR}(-4)$ & $-0.127 * * *$ & -0.026 & $-0.049 * *$ & $-0.047 * *$ \\
\hline$p$-value & 0.000 & 0.444 & 0.047 & 0.042 \\
\hline KORLR(-5) & -0.012 & 0.017 & $-0.053 * *$ & -0.008 \\
\hline$p$-value & 0.700 & 0.614 & 0.032 & 0.720 \\
\hline $\operatorname{TWLR}(-1)$ & 0.002 & -0.024 & 0.025 & -0.031 \\
\hline$p$-value & 0.953 & 0.474 & 0.320 & 0.189 \\
\hline $\operatorname{TWLR}(-2)$ & 0.031 & 0.054 & 0.014 & 0.017 \\
\hline$p$-value & 0.313 & 0.104 & 0.576 & 0.455 \\
\hline $\operatorname{TWLR}(-3)$ & 0.049 & $0.068 * *$ & 0.019 & -0.008 \\
\hline$p$-value & 0.110 & 0.042 & 0.447 & 0.744 \\
\hline $\operatorname{TWLR}(-4)$ & $0.054 *$ & -0.012 & 0.002 & 0.001 \\
\hline$p$-value & 0.078 & 0.718 & 0.940 & 0.962 \\
\hline TWLR $(-5)$ & -0.012 & 0.011 & 0.023 & -0.028 \\
\hline$p$-value & 0.703 & 0.745 & 0.361 & 0.224 \\
\hline Const. & 0.008 & 0.022 & 0.012 & 0.014 \\
\hline$p$-value & 0.737 & 0.406 & 0.556 & 0.447 \\
\hline LL & -6421.386 & -6725.901 & -5676.178 & -5446.435 \\
\hline AIC & 3.604 & 3.774 & 3.187 & 3.059 \\
\hline $\mathrm{SC}$ & 3.640 & 3.811 & 3.224 & 3.095 \\
\hline
\end{tabular}

Notes: JPLR: Japanese stock return; CHLR: Chinese stock return; KORLR: Korean stock return; TWLR: Taiwanese stock return.

$\operatorname{JPLR}(-k)$ : the $k$ th lag of Japanese stock return; CHLR $(-k)$ : the $k$ th lag of Chinese stock return; KORLR $(-k)$ : the $k$ th lag of Korean stock return; TWLR $(-k)$ : the $k$ th lag of Taiwanese stock return; Const.: constant term of the VAR model.

$* * *, * *$, and $*$ denote $1 \%, 5 \%$, and $10 \%$ significance levels, respectively.

Bold figures mean statistically significantly positive parameter estimates.

LL: the log-likelihood value.

AIC: Akaike's Information Criterion.

SC: Schwarz Criterion. 


\section{Empirical results}

This section explains our empirical results. First, Table 2 displays the estimation results of the VAR model for our former subsample period. We note that the bold figures indicate the statistically significantly positive return transmission. As this table shows, we mainly find the cross-country return transmission in the four Asian stock markets as follows. First, (1) Japanese stock returns transmit to the next day's Chinese, Korean, and Taiwanese stock returns. Second, (2) Korean stock returns transmit to the next day's Japanese and Taiwanese stock returns. Third, (3) Taiwanese stock returns transmit to the next day's Korean stock returns.

Further, we also find the autoregressive return relations for the four Asian stock markets as follows. First, (1) Chinese stock returns transmit to their own future stock returns. Second, (2) Korean stock returns transmit to their own future stock returns. Third, (3) Taiwanese stock returns transmit to their own future stock returns.

Next, Table 3 exhibits the estimation results of the VAR model for our latter subsample period. We again note that the bold figures indicate the statistically significantly positive return transmission. As Table 3 shows, regarding rapid cross-country return transmission in the four Asian stock markets, we find that Korean stock returns transmit to the next day's Japanese and Taiwanese stock returns. Further, regarding the rapid autoregressive return relations, we also find that Korean stock returns again transmit to their own future stock returns in the latter subsample period.

Overall, our results suggest that both rapid cross-country and fast autoregressive return transmission between the four Asian stock markets recently decreased, and the effects from the Japanese stock market to the other three Asian stock markets became weaker. In addition, our results also suggest that the return transmission effect from the Chinese stock market to the other three Asian stock markets is generally weak, also indicating that the Chinese stock market evolves autonomously.

\section{Conclusions}

This paper investigated the return transmission between four Asian stock markets in Japan, China, Korea, and Taiwan. The main findings from our analyses are as follows. That is, for our former subsample period, first, (1) Japanese stock returns transmit to the next day's Chinese, Korean, and Taiwanese stock returns. Second, (2) Korean stock returns transmit to the next day's Japanese and Taiwanese stock returns. Third, (3) Taiwanese stock returns transmit to the next day's Korean stock returns. Fourth, (4) Chinese stock returns transmit to their own future stock returns. Fifth, (5) Korean stock returns transmit to their own future stock returns. Sixth, (6) Taiwanese stock returns transmit to their own future stock returns.

Next, for our latter subsample period, first, (1) Korean stock returns transmit to the next day's Japanese and Taiwanese stock returns. Second, (2) Korean stock returns again transmit to their own future stock returns.

Overall, our results suggested that both rapid cross-country and fast autoregressive return 
transmission between the four Asian stock markets recently decreased, and the effects from the Japanese stock market to the other three Asian stock markets became weaker. In addition, our results also indicated that the return transmission effect from the Chinese stock market to the other three Asian stock markets is generally weak, also meaning that the Chinese stock market evolves autonomously.

We believe that our results are much useful for deepening our understanding and knowledge of Asian stock market linkages, and further research using more advanced techniques is one of our future works.

\section{Acknowledgement}

The author is grateful to the kind article invitation from this journal. The author also thanks the financial support of a Grant-in-Aid for Scientific Research from the Japan Society for the Promotion of Science and the Chuo University Personal Research Grant. In addition, the author appreciates an anonymous referee for the supportive comments on this paper. Furthermore, the author is also very grateful to the Editor, Lucy $\mathrm{Xu}$, for her skilful editorship of this paper and supportive comments.

\section{References}

Arouri, M. E. H., Jouini, J., \& Nguyen, D. K. (2011a). Volatility spillovers between oil prices and stock sector returns: Implications for portfolio management. Journal of International Money and Finance, 30, 1387-1405. https://doi.org/10.1016/j.jimonfin.2011.07.008

Arouri, M. E. H., Lahiani, A., \& Nguyen, D. K. (2011b). Return and volatility transmission between world oil prices and stock markets of the GCC countries. Economic Modelling, 28, 1815-1825. https://doi.org/10.1016/j.econmod.2011.03.012

Arouri, M. E. H., Jouini, J., \& Nguyen, D. K. (2012). On the impacts of oil price fluctuations on European equity markets: Volatility spillover and hedging effectiveness. Energy Economics, 34, 611-617. https://doi.org/10.1016/j.eneco.2011.08.009

Huo, R., \& Ahmed, A. D. (2017). Return and volatility spillovers effects: Evaluating the impact of Shanghai-Hong Kong Stock Connect. Economic Modelling, 61, 260-272. https://doi.org/10.1016/j.econmod.2016.09.021

Roy, R. P., \& Roy, S. S. (2017). Financial contagion and volatility spillover: An exploration into Indian commodity derivative market. Economic Modelling, 67, 368-380. https://doi.org/10.1016/j.econmod.2017.02.019

Sadorsky, P. (2012). Correlations and volatility spillovers between oil prices and the stock prices of clean energy and technology companies. Energy Economics, 34, 248-255. http://dx.doi.org/10.1016/j.eneco.2011.03.006

Syriopoulos, T., Makram, B., \& Boubaker, A. (2015). Stock market volatility spillovers and portfolio hedging: BRICS and the financial crisis. International Review of Financial Analysis, 39, 7-18. https://doi.org/10.1016/j.irfa.2015.01.015 


\section{Macrothink}

Journal of Management Research

ISSN 1941-899X

2019, Vol. 11, No. 4

Tsuji, C. (2018a). Return transmission and asymmetric volatility spillovers between oil futures and oil equities: New DCC-MEGARCH analyses. Economic Modelling, 74, 167-185. https://doi.org/10.1016/j.econmod.2018.05.007

Tsuji, C. (2018b). New DCC analyses of return transmission, volatility spillovers, and optimal hedging among oil futures and oil equities in oil-producing countries. Applied Energy, 229, 1202-1217. https://doi.org/10.1016/j.apenergy.2018.08.008

Tsuji, C. (2019). Correlation and spillover effects between the US and international banking sectors: New evidence and implications for risk management. International Review of Financial Analysis, forthcoming. 